\title{
Activation of TGR5 alleviates inflammation in rheumatoid arthritis peripheral blood mononuclear cells and in mice with collagen II-induced arthritis
}

\author{
ZHE-YONG LI $^{1}$, JING-JING ZHOU ${ }^{2}$, CHUN-LEI LUO ${ }^{3}$ and LE-MENG ZHANG ${ }^{4}$ \\ ${ }^{1}$ Department of General Surgery, Sir Run Run Shaw Hospital, Hangzhou, Zhejiang 310017; \\ ${ }^{2}$ Department of Rheumatology, Navy General Hospital, Beijing 100048; ${ }^{3}$ Department of Nephrology, \\ Ningbo First Hospital, Ningbo, Zhejiang 3150102; ${ }^{4}$ Thoracic Medicine Department 1, \\ Hunan Cancer Hospital, Changsha, Hunan 410013, P.R. China
}

Received June 8, 2018; Accepted April 2, 2019

DOI: $10.3892 / \mathrm{mmr} .2019 .10711$

\begin{abstract}
Rheumatoid arthritis (RA) is characterized by chronic inflammatory synovitis resulting in progressive joint destruction. Persistent synovial inflammation is induced by activation of various inflammatory cells. G-protein-coupled bile acid receptor 1 (TGR5) is a G-protein-coupled receptor activated by various bile acids, which has been reported to act as a key adaptor in regulating various signaling pathways involved in inflammatory responses and a diverse array of physiological processes, including bile acid synthesis, lipid and carbohydrate metabolism, carcinogenesis, immunity and inflammation. In the present study, TGR5 expression was detected in RA peripheral blood mononuclear cells (PBMCs),
\end{abstract}

Correspondence to: Dr Jing-Jing Zhou, Department of Rheumatology, Navy General Hospital, 6 Fucheng Road, Haidian, Beijing 100048, P.R. China

E-mail: shamanhua1986@163.com

Abbreviations: RA, rheumatoid arthritis; PBMC, peripheral blood mononuclear cell; HC, healthy control; TGR5, G-protein-coupled bile acid receptor 1; RF, rheumatoid factor; CRP, C-reactive protein; ESR, erythrocyte sedimentation rate; MMP, matrix metalloproteinase; anti-CCP, anti-cyclic citrullinated peptide; DAS28, 28-Joint Disease Activity Score; ELISA, enzyme-linked immunosorbent assay; HAQ, Health Assessment Questionnaire; RT-qPCR, reverse transcription-quantitative polymerase chain reaction; NF- $\kappa \mathrm{B}$, nuclear

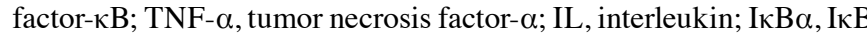
kinase $\alpha$; CIA, collagen II-induced arthritis; ACR, American College of Rheumatology; 28TJC, 28-joint tender joint count; 28SJC, 28-joint swollen joint count; PtGA, patient global assessment of disease activity; PrGA, provider global assessment of disease activity; cDNA, complementary DNA; CII, collagen type II; DMARD, disease-modifying anti-rheumatic drug; FLS, fibroblast-like synoviocyte; LCA, lithocholic acid; LPS, lipopolysaccharide

Key words: G-protein-coupled bile acid receptor 1, rheumatoid arthritis, peripheral blood mononuclear cells, NF- $\kappa \mathrm{B}$, collagen II-induced arthritis, proinflammatory cytokines, arthritis score and its association with clinical disease activity, histological synovitis severity and radiological joint destruction was analyzed. Subsequently, the role and potential underlying mechanisms of TGR5 in the PBMCs of patients with RA and mice with collagen II-induced arthritis (CIA) were investigated. PBMCs were obtained from 50 patients with RA and 40 healthy controls (HCs). The mRNA and protein expression levels of TGR5 were detected in PBMCs via reverse transcription-quantitative polymerase chain reaction (RT-qPCR) and immunofluorescence staining, respectively. Additionally, the levels of proinflammatory cytokines were analyzed by RT-qPCR and enzyme-linked immunosorbent assay (ELISA). The activation of nuclear factor- $\kappa \mathrm{B}(\mathrm{NF}-\kappa \mathrm{B})$ and $\mathrm{I} \kappa \mathrm{B}$ kinase a was determined via western blot analysis. The anti-arthritic and anti-inflammatory effects of LCA on mice with CIA were then investigated. The arthritis score was assessed, and the protein levels of proinflammatory cytokines in the plasma of mice were detected via ELISA. TGR 5 mRNA expression was significantly downregulated in the PBMCs of patients with RA compared with in those of the HCs $(0.53 \pm 0.58$ for patients vs. $1.49 \pm 0.83$ for $\mathrm{HCs}$; $\mathrm{P}<0.001)$; similar findings were observed at the protein level. The mRNA expression levels of TGR5 in the PBMCs of patients with RA with a high 28-Joint Disease Activity Score (DAS28) were significantly decreased compared with in patients with a low DAS28 $(0.81 \pm 0.65$ for low score vs. $0.35 \pm 0.46$ for high score; $\mathrm{P}=0.002$ ). Furthermore, TGR5 expression was significantly correlated with the levels of $\mathrm{C}$-reactive protein $(\mathrm{r}=-0.429 ; \mathrm{P}=0.002)$ and the DAS28 ( $\mathrm{r}=-0.383 ; \mathrm{P}=0.006)$. RT-qPCR and ELISA analyses indicated that lithocholic acid (LCA, $10 \mathrm{mg} / \mathrm{kg} / \mathrm{day}$ ) attenuated lipopolysaccharide-induced proinflammatory cytokine production via inhibition of $\mathrm{NF}-\kappa \mathrm{B}$ activity in the PBMCs of patients with RA. In addition, the arthritis score was significantly decreased in LCA-treated CIA mice compared with in non-treated CIA mice. The increased production of tumor necrosis factor- $\alpha$, interleukin (IL)-1 $\beta$, IL-6 and IL-8 was significantly reduced in the plasma of LCA-treated CIA mice compared with the control. In conclusion, TGR5 may contribute to the inflammation of PBMCs in patients with RA and mice with CIA. 


\section{Introduction}

Rheumatoid arthritis (RA) is characterized by chronic inflammatory synovitis resulting in progressive joint destruction (1). Persistent synovial inflammation is considered to be a characteristic feature of RA, leading and contributing to cartilage and bone destruction, and subsequent disability in RA (2); however, there is no effective treatment for RA, and the precise etiology and underlying mechanisms remain unclear. At present, various cell types have been reported to serve distinct, complex and interconnected roles in the synovial inflammation of RA, including monocytes/macrophages, T cells, B cells, fibroblast-like synoviocytes (FLSs) and osteoclasts $(3,4)$. For example, FLSs in the intimal lining of the synovium serve an important role in RA via the hyperproduction of proinflammatory cytokines and matrix metalloproteinases (MMPs), potentially resulting in cartilage destruction (5).

Monocytes/macrophages are recognized as a prominent joint-specific determinant; their activation may lead to inflammation, acute phase reaction and joint destruction in acute and chronic RA by promoting the production of key proinflammatory cytokines, including tumor necrosis factor (TNF)- $\alpha$, interleukin (IL)- $1 \beta$ and MMPs (6-8). In addition, these cells are a potent source of chemokines, which recruit additional leukocytes to the inflamed joint to exacerbate the disease process. Furthermore, monocytes can differentiate into osteoclasts, and have also been reported to enhance the production of the osteoclastogenic cytokine IL-17 by $\mathrm{CD} 4^{+}$ $\mathrm{T}$ cells, in turn further contributing to bone erosion, and focal and systemic osteoporosis $(6,9,10)$. The importance of the role of macrophages in RA is supported by findings reporting these cells to be a reliable biomarker for treatment response and associated with disease activity markers (11-13). Nuclear factor $-\kappa \mathrm{B}(\mathrm{NF}-\kappa \mathrm{B})$ has received considerable attention as a key regulator of immunology, inflammation and cancer development, and has been reported to influence the pathogenesis and progression of RA $(14,15)$. Activation of NF- $\kappa$ B promotes the secretion of cytokines such as TNF- $\alpha$ and IL-1 $\beta$ by the monocytes/macrophages of patients with RA (16). Therefore, increasing attention in the field of RA research has been placed on monocytes/macrophages as potential therapeutic targets (7).

G-protein-coupled bile acid receptor 1 (TGR5) is a G-protein-coupled receptor, which responds to various bile acids by activating transcriptional networks and/or signaling cascades, which regulate a diverse array of physiological processes, including bile acid synthesis, lipid and carbohydrate metabolism, carcinogenesis and inflammation $(17,18)$. TGR5 gene expression is diffusely distributed in the endocrine glands, muscles, immune organs, adipocytes, spinal cord and enteric nervous system (19). Human and mouse TGR5 exhibit similar affinity for the different bile acid species; the highest affinity is for lithocholic acid (LCA), followed by deoxycholic acid, chenodeoxycholic acid and cholic acid $(20,21)$. Since the identification of dedicated bile acid receptors, there has been an increased interest in modulating these targets pharmacologically. For example, the observation that TGR5 induces the secretion of clinically relevant glucagon-like peptide 1 has promoted the development of a novel class of drugs for the treatment of type 2 diabetes mellitus (22). Regarding the potential for manipulating TGR5 within the context of immunology and inflammation, studies on rabbit alveolar macrophages and human hepatic Kupffer cells have suggested that TGR5 activation suppresses lipopolysaccharide (LPS)-induced production of the proinflammatory cytokines TNF- $\alpha$, IL-1, IL-6 and IL-8 $(23,24)$. The potential for targeting TGR5 in immunology has been further validated by the finding that TGR5 activation inhibits atherosclerosis by reducing macrophage inflammation and lipid loading (25). Furthermore, previous studies on mouse bone marrow-derived macrophages and human macrophage subsets revealed that TGR5 activation negatively regulates hepatic inflammatory responses via impaired $\mathrm{NF}-\kappa \mathrm{B}$ signaling pathways $(26,27)$.

RA is one of the most severe chronic diseases, which is caused by persistent synovial inflammation and bone destruction. TGR5 is important for inflammatory signaling pathways; however, at present, the expression and pathophysiological role of TGR5 in RA have not been elaborated. Therefore, in the present study, TGR5 expression in RA peripheral blood mononuclear cells (PBMCs) was determined, and its association with clinical disease activity, histological synovitis severity and radiological joint destruction was investigated. Subsequently, the role of TGR5 in PBMC inflammation and the potential mechanisms underlying its effects were determined. Finally, the anti-arthritic and anti-inflammatory effects of LCA on mice with collagen type II (CII)-induced arthritis (CIA) were investigated.

\section{Materials and methods}

Patients. A total of 50 Chinese patients with RA who fulfilled the 1987 revised criteria of the American College of Rheumatology (ACR) (28) or the 2010 ACR/European League against Rheumatism classification criteria for RA (29) were recruited from the Department of Rheumatology and Orthopedics of the Hunan Cancer Hospital (Changsha, China). All patients presented with active disease, described as the presence of a 28-Joint Disease Activity Score (DAS28) of 23.2. Age, gender or disease duration did not differ among the patients with RA and healthy controls. In total, 11 RA patients were male and 39 were female, with a mean age of 59 (49-64) years. In the healthy control group, 14 patients were male and 26 were female, with a mean age of $36(29-48)$ years. The date range of assessment/sample collection for both groups was from June 2016 to October 2018. The present study was conducted in compliance with the Helsinki Declaration principles. All patients provided written informed consent

Clinical assessments. The clinical data of all patients with RA were collected at baseline, including the 28 -joint tender and swollen joint counts (28TJC and 28SJC, respectively), patient and provider global assessment of disease activity (PtGA and PrGA, respectively) scores, visual analog scale score for pain, Chinese language version of the Stanford Health Assessment Questionnaire (HAQ) score (30), erythrocyte sedimentation rate (ESR), C-reactive protein (CRP) level, rheumatoid factor (RF) level and anti-cyclic citrullinated peptide (anti-CCP) antibody level. Disease activity was assessed using the DAS28 with four variables, including CRP level [DAS28 (4)-CRP] (31). 
Table I. Primers for reverse transcription-quantitative polymerase chain reaction.

\begin{tabular}{ll}
\hline Gene & \\
\hline$\beta$-actin & \multicolumn{1}{c}{ Sequence } \\
IL-6 & Sense: 5'-GGACTTCGAGCAAGAGATGG-3' \\
& Antisense: 5'-TGTGTTGGCGTACAGGTCTTTG-3' \\
IL-8 & Sense: 5'-CTGCGCAGCTTTAAGGAGTTC-3' \\
& Antisense: 5'-CAATCTGAGGTGCCCATGCTA-3' \\
IL-1 $\beta$ & Sense: 5'-GTGCAGAGGGTTGTGGAGAAGTTT-3' \\
TNF-a & Antisense:5'-TCACTGGCATCTTCACTGATTCTTG-3' \\
& Sense: 5'-CCAGCTACGAATCTCCGACC-3' \\
TGR5 & Antisense: 5'-CATGGCCACAACAACTGACG-3' \\
& Sense: 5'-GCTAAGAGGGAGAGAAGCAACTACA-3' \\
& Antisense: 5'-GAAGAGGCTGAGGAACAAGCA-3' \\
& Sense: 5'-CCCAGGCTATCTTCCCAGC-3'
\end{tabular}

IL, interleukin; TGR5, G-protein-coupled bile acid receptor 1; TNF- $\alpha$, tumor necrosis factor- $\alpha$.

Isolation and culture of human PBMCs. Heparinized whole blood was collected from 50 patients with RA and 40 healthy controls (HCs). PBMCs were separated via Ficoll/Paque density gradient centrifugation at $400 \mathrm{x}$ g for $30 \mathrm{~min}$ at $18-20^{\circ} \mathrm{C}$. Cells were then re-suspended in $\alpha$-Minimal Essential Medium with $10 \%$ fetal bovine serum (Gibco; Thermo Fisher Scientific, Inc.) and plated in a $37^{\circ} \mathrm{C}$ humidified incubator with $5 \% \mathrm{CO}_{2}$. On the following day, the suspended cells were removed and washed thoroughly, and the adherent cells were collected and plated. PBMCs were first treated with various concentrations $(0,50$ and $100 \mu \mathrm{M})$ of LCA for $60 \mathrm{~min}$, and then treated with LPS (100 ng/ml) for $12 \mathrm{~h}$, mRNA was extracted, and the culture medium was collected for ELISA analysis.

Immunofluorescence staining. The PBMCs $\left(8 \times 10^{5}\right.$ cells/well) were plated on 24-well culture plates with coverslips, fixed in $4 \%$ paraformaldehyde for $20 \mathrm{~min}$ at room temperature, permeabilized with $0.2 \%$ Triton X-100 for $10 \mathrm{~min}$ at room temperature, and blocked in PBS containing 3\% bovine serum albumin (Abcam) for $30 \mathrm{~min}$ at $37^{\circ} \mathrm{C}$. The cells were then incubated in PBS containing rabbit anti-human polyclonal antibody against TGR5 (10 $\mu \mathrm{g} / \mathrm{ml}$; ab72608; Abcam) overnight at $4^{\circ} \mathrm{C}$, and subsequently incubated with Alexa Fluor $^{\circledR}$ 633-conjugated goat anti-rabbit immunoglobulin $\mathrm{G}$ secondary antibodies (1:1,000; cat. no. A-21071; Invitrogen; Thermo Fisher Scientific, Inc.) for $1 \mathrm{~h}$ at $37^{\circ} \mathrm{C}$. Subsequently, DAPI (Sigma-Aldrich; Merck KGaA) was used to stain the cell nuclei at a concentration of $1.43 \mu \mathrm{M}$ for $3 \mathrm{~min}$ at room temperature, and cells were mounted using ProLong ${ }^{\circledR}$ Gold Antifade Reagent (cat. no. P36934; Invitrogen; Thermo Fisher Scientific, Inc.). The images were acquired using a 160 Zeiss LSM 510 Confocal Imaging system (Zeiss GmbH).

Reverse transcription-quantitative polymerase chain reaction $(R T-q P C R)$. Total RNA was extracted from PBMCs using the RNAiso Plus reagent (Takara Bio, Inc.) according to the manufacturer's protocols. First-strand complementary DNA (cDNA) was synthesized from each total RNA sample using a
PrimeScript 1st Strand cDNA Synthesis kit (Takara Bio, Inc.) at $37^{\circ} \mathrm{C}$ for $15 \mathrm{~min}, 85^{\circ} \mathrm{C}$ for $5 \mathrm{sec}$. qPCR was performed using the QuantiTect ${ }^{\mathrm{TM}}$ SYBR Green PCR kit (Takara Bio, Inc.) on the Roche LightCycler480 sequence detector system (Roche Diagnostics) according to the manufacturer's protocols. The qPCR conditions were as follows: Denaturation at $95^{\circ} \mathrm{C}$ for $30 \mathrm{sec}$, then $95^{\circ} \mathrm{C}$ for $5 \mathrm{sec}$ and $60^{\circ} \mathrm{C}$ for $30 \mathrm{sec}$ for $40-50$ cycles. The sequences of the primers used in the study are presented in Table I, and these were synthesized by Invitrogen (Thermo Fisher Scientific, Inc.). PCR amplification of the housekeeping gene $\beta$-actin was performed for each sample as a control for sample loading. Normalization and quantification of the PCR signals was performed by comparing the cycle threshold value of the gene of interest, in triplicate, with $\beta$-actin. The fold change in gene expression relative to the control was calculated using the $2^{-\Delta \Delta \mathrm{Cq}}$ method (32). Data are presented as the mean \pm standard deviation of three independent experiments and analyzed with the LightCycler480 software release 1.5.0 (Roche Diagnostics).

Western blot analysis. PBMCs were collected and lysed to obtain proteins using a RIPA buffer (Cell Signaling Technologies, Inc.), whereas nuclear protein was separated using a NE-PER ${ }^{\mathrm{TM}}$ Nuclear and Cytoplasmic Extraction kit (Pierce; Thermo Fisher Scientific, Inc.). Protein concentration was measured using bicinchoninic acid Protein Assay kit from Bio-Rad Laboratories, Inc. Proteins (50 $\mu \mathrm{g} /$ lane) were separated by $12 \%$ SDS-PAGE under denaturing conditions, and were electrotransferred to nitrocellulose membranes. The membranes were then blocked with $5 \%$ non-fat milk in $0.1 \%$ TBS-Tween 20 for $1 \mathrm{~h}$ at room temperature, and were probed with antibodies against TGR5 (cat. no. ab72608; Abcam),

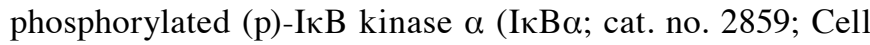
Signaling Technologies, Inc.), total (T)-ІкB $\alpha$ (cat. no. 9249; Cell Signaling Technologies, Inc.) and p-NF-кB (cat. no. 3033; Cell Signaling Technologies, Inc.; all 1:1,000); GAPDH (cat. no. 5174; Cell Signaling Technologies, Inc.; 1:1,000) and histone H3 (cat. no. 9275; Cell Signaling Technologies, 
Inc.; 1:2,000) overnight at $4^{\circ} \mathrm{C}$. For the detection of proteins, membranes were then incubated for $1 \mathrm{~h}$ at room temperature with horseradish peroxidase-conjugated secondary antibody (cat. no. E030120-01; EarthOx Life Sciences; 1:5,000). Immunoreactive bands were visualized using an enhanced chemiluminescence reagent (EMD Millipore). Protein bands were semi-quantified via densitometric analyses using a G:BOX Gel \& Blot Imaging Series (Syngene Europe) and ImageQuant LAS500 (GE Life Sciences). Phosphorylated protein expression was normalized to total protein expression, and expressed as a fold change relative to the untreated control. Data are presented as the means \pm standard deviation of three independent experiments.

Enzyme-linked immunosorbent assay (ELISA). The quantities of TNF- $\alpha$ (cat. no. DTA00D, R\&D Systems, Inc.), IL-1 $\beta$ (cat. no. DLB50, R\&D Systems, Inc.), IL-6 (cat. no. D6050, R\&D Systems, Inc.) and IL-8 (cat. no. D8000C, R\&D Systems, Inc.) in culture supernatants were measured via ELISA according to the manufacturer's protocols. The quantities of TNF- $\alpha$ (cat. no. MTA00B, R\&D Systems, Inc.), IL-1 $\beta$ (cat. no. MLB00C, R\&D Systems, Inc.), IL-6 (cat. no. M6000B, R\&D Systems, Inc.) and IL-8 (cat. no. LS-F55769, LifeSpan BioSciences, Inc.) in mouse blood samples were measured via ELISA according to the manufacturer's protocol. Briefly, PBMCs were subjected to different treatments. Then, mouse blood samples were centrifuged at $1,006.2 \mathrm{x}$ g for $15 \mathrm{~min}$ to separate the blood plasma at room temperature. The culture supernatant or the blood plasma were mixed with the assay buffer and added to anti-TNF- $\alpha$, IL- $1 \beta$, IL- 6 and IL- 8 antibody-coated wells. Horseradish peroxidase-conjugated anti-human TNF- $\alpha$, IL-1 $\beta$, IL-6, and IL-8 monoclonal antibodies were added and incubated at $37^{\circ} \mathrm{C}$ for $2 \mathrm{~h}$, followed by incubation with colorimetric (tetramethylbenzidine) solution for a further $10 \mathrm{~min}$. The relative absorbance was measured at $450 \mathrm{~nm}$, and three independent experiments were performed for each condition.

Animal study. This study was conducted on male DAB/1J mice (age, 6-8 weeks; 18-22 g) obtained from Beijing HFK Bioscience Co., Ltd. A total of 30 mice were divided into three equal groups: Negative controls (NCs), experimental arthritis controls not treated with LCA and experimental arthritis group treated with LCA (10 mg/kg/day; Sigma-Aldrich; Merck $\mathrm{KGaA})$. The NCs did not have CIA. The mice were housed in a room on a 12-h light/dark cycle under specific pathogen-free conditions, at a temperature of $22-26^{\circ} \mathrm{C}$ and relative humidity of 55-65\%. All experiments were conducted in compliance with the National Institutes of Health guidelines for the care and use of laboratory animals (33). The study was approved by the Institutional Animal and Clinical Committees of Hunan Cancer Hospital.

Induction of CIA and LCA treatment. CIA was induced according to the previously described method by Brand et al (34) in the experimental arthritis controls not treated with LCA and experimental arthritis group treated with LCA mouse groups. Briefly, native chick CII (Chondrex, Inc.) was dissolved in $10 \mathrm{mM}$ acetic acid to a $1 \mathrm{mg} / \mathrm{ml}$ concentration, and was emulsified in an equal volume of Freund's complete adjuvant (Sigma-Aldrich; Merck KGaA). Each mouse received two intradermal injections of emulsion $(0.1 \mathrm{ml})$ containing CII (1 $\mathrm{mg} / \mathrm{ml})$ and Freund's complete adjuvant at two separated sites tail on days 1 and 21 .

For LCA treatment, LCA was dissolved and freshly diluted in PBS. PBS and LCA (10 mg/kg/day) were orally administered via a gastric tube once a day from day 21 to day 42 following the first immunization. Both NCs and experimental arthritis controls not treated with LCA were treated with PBS.

Arthritis score. The arthritis score was assessed once every 3 days following the initiation of LCA treatment. The severity of arthritis was measured in a double manner using the semi-quantitative clinical scoring system described by Yoo et al (35) (0, no arthritis; 1, definite erythema and swelling of the ankle or one digit; 2, two or more joints involved or mild erythema and swelling of the entire paw; 3 , erythema and swelling extending from the ankle to the metatarsal joints of the entire paw and all digits; and 4, ankylosing deformity with severe joint erythema and swelling). The arthritis score for each mouse was the sum of all paw scores (yielding a score between 0 and 16). On day 42, the mice were sacrificed and blood was collected for serum separation.

Statistical analysis. Statistical analyses were performed using SPSS 13.0 software (SPSS, Inc.). For categorical variables, data are presented as frequencies and percentages. For continuous variables, data are presented as the means \pm standard deviation, or the median and interquartile range. Wilcoxon rank-sum test was used to compare the expression of TGR5 in the PBMCs of patients with RA and HCs, and the arthritis score in the experimental arthritis controls and experimental arthritis controls treated with LCA. One-way or Welch's ANOVA followed by least significant difference post-hoc tests were performed to compare the expression of TNF- $\alpha$, IL-1 $\beta$, IL- 6 and IL- 8 in the culture supernatant or the blood plasma, and the expression of $\mathrm{p}-\mathrm{NF}-\kappa \mathrm{B}$ and $\mathrm{p}-\mathrm{I} \kappa \mathrm{B} \alpha$ in the PBMCs treated with various LCA or not treated with LCA. Spearman's rank order correlation test was used to assess the correlation between TGR5 expression in RA PBMCs and clinical parameters. $\mathrm{P}<0.05$ was considered to indicate a statistically significant difference.

\section{Results}

Characteristics of the study patients. Table II presents the baseline demographic and clinical features of individuals in the study. The gender ratio did not differ between the patients in the RA and $\mathrm{HC}$ groups. Among the patients with RA, 48\% (24/50) had not previously taken corticosteroids or disease-modifying anti-rheumatic drugs (DMARDs). The majority of patients had taken only Chinese herbal medicine and/or painkillers to relieve arthralgia. At recruitment, $18 \%(9 / 50)$ had taken corticosteroids alone. The remaining $34 \%(17 / 50)$ received treatment with one or more DMARD, including methotrexate, leflunomide, sulfasalazine, hydroxychloroquine and etanercept.

Expression of TGR5 is downregulated in the PBMCs of patients with RA. The mRNA expression levels of TGR5 in PBMCs were evaluated in 50 patients with RA and $40 \mathrm{HCs}$. The expression of TGR 5 mRNA in the PBMCs of patients with 
Table II. Baseline demographic and clinical features of patients with RA and HCs.

\begin{tabular}{|c|c|c|}
\hline Characteristic & Patients with RA $(\mathrm{n}=50)$ & $\mathrm{HC}(\mathrm{n}=40)$ \\
\hline \multicolumn{3}{|l|}{ Demographic } \\
\hline Age [years; median (IQR)] & $59(49-64)$ & $36(29-48)$ \\
\hline Female $[\mathrm{n}(\%)]$ & $39(78)$ & $26(65)$ \\
\hline \multicolumn{3}{|l|}{ Disease status } \\
\hline Disease duration [months; median (IQR)] & $34(12-106)$ & NA \\
\hline ESR $[\mathrm{mm} / \mathrm{h} ;$ median (IQR)] & $75(54-105)$ & $11(3-21)$ \\
\hline CRP [mg/dl; median (IQR)] & $4.02(1.19-5.75)$ & $0.11(0.02-0.23)$ \\
\hline Rheumatoid factor-positive [n (\%)] & $47(94)$ & NA \\
\hline Anti-CCP-positive [n (\%)] & $43(86)$ & NA \\
\hline DAS28 [median (IQR)] & $5.5(4.6 \sim 6.3)$ & NA \\
\hline \multicolumn{3}{|l|}{ Previous medications [n (\%)] } \\
\hline Corticosteroids & $22(50)$ & NA \\
\hline Methotrexate & $20(40)$ & NA \\
\hline Leflunomide & $5(10)$ & NA \\
\hline Sulfasalazine & $4(8)$ & NA \\
\hline Hydroxychloroquine & $6(12)$ & NA \\
\hline Etanercept & $2(4)$ & NA \\
\hline
\end{tabular}

Anti-CCP, anti-cyclic citrullinated peptide antibodies; CRP, C-reactive protein; DAS28, Disease Activity Score 28-joint assessment; ESR, erythrocyte sedimentation rate; HC, healthy control; IQR, interquartile range; NA, not applicable; RA, rheumatoid arthritis; RF, rheumatoid factor.

RA was significantly decreased compared with in the $\mathrm{HCs}$ $(0.53 \pm 0.58$ vs. $1.49 \pm 0.83 ; \mathrm{P}<0.001$; Fig. $1 \mathrm{~A})$. Additionally, the expression of TGR5 mRNA in the PBMCs of patients with RA with a high DAS28 was significantly decreased compared with in patients with a low DAS28 $(0.35 \pm 0.46$ vs. $0.81 \pm 0.65$, respectively; $\mathrm{P}=0.002$; Fig. 1B). The expression of TGR5 mRNA in the PBMCs of the patients with RA with either a high or low DAS28 was also significantly lower than that of the HCs $(0.81 \pm 0.65$ vs. $1.49 \pm 0.83, \mathrm{P}<0.001 ; 0.35 \pm 0.46$ vs. $1.49 \pm 0.83$, $\mathrm{P}=0.002$; Fig. 1B). The number of patients with $\mathrm{RA}$ with a DAS28 score of $\geq 5.1$ was 30 . Of these patients, $50 \%(15 / 30)$ had never taken corticosteroids or DMARDs. At recruitment, $20 \%(6 / 30)$ had taken corticosteroids alone. The remaining $30 \%(9 / 30)$ received treatment with one or more DMARDs, including methotrexate, leflunomide, sulfasalazine, hydroxychloroquine or etanercept. Patients did not exhibit any obvious side effects after taking DMARDs. Immunofluorescence staining revealed markedly reduced expression of TGR5 in the PBMCs of patients with RA compared with in the PBMCs of HCs (Fig. 1C).

Expression of TGR5 $m R N A$ in the PBMCs of patients with RA demonstrates a negative correlation with clinical parameters. Spearman's rank order correlation test revealed significant correlations between the mRNA expression levels of TGR5 in PBMCs and the CRP level ( $\mathrm{r}=-0.429, \mathrm{P}=0.002)$, and the DAS28 ( $r=-0.383, P=0.006)$ of patients (Fig. 2). There was no significant correlation between TGR5 mRNA expression and 28TJC, 28SJC, PtGA score, PrGA score, HAQ score, RF level, anti-CCP level, ESR, the simplified disease activity index and the clinical disease activity index (respectively: $r=0.043$,
$\mathrm{P}=0.763 ; \mathrm{r}=-0.072 \mathrm{P}=0.611 ; \mathrm{r}=-0.011, \mathrm{P}=0.939 ; \mathrm{r}=0.185$, $\mathrm{P}=0.188 ; \mathrm{r}=0.172, \mathrm{P}=0.223 ; \mathrm{r}=0.049, \mathrm{P}=0.732 ; \mathrm{r}=0.188$, $\mathrm{P}=0182 ; \mathrm{r}=0.067, \mathrm{P}=0.642 ; \mathrm{r}=-0.099, \mathrm{P}=0.544$; and $\mathrm{r}=-0.106$, $\mathrm{P}=0.455)$.

LCA attenuates LPS-induced proinflammatory cytokine production in the PBMCs of patients with RA. LPS is a potent endotoxin involved in the progression of RA diseases (36). LPS treatment $(100 \mathrm{ng} / \mathrm{ml})$ for $12 \mathrm{~h}$ markedly increased the mRNA and protein expression levels of TNF- $\alpha$, IL-1 $\beta$, IL-6 and IL-8 in the PBMCs of patients with RA by between 3- and 10-fold (Fig. 3). Pretreatment of PBMCs with LCA (50 and $100 \mu \mathrm{M})$ for 60 min significantly inhibited LPS-induced TNF- $\alpha$, IL-1 $\beta$, IL-6 and IL- 8 mRNA expression and protein release into the supernatant in a concentration-dependent manner (Fig. 3).

LCA inhibits LPS-induced $N F-\kappa B$ and $I \kappa B \alpha$ activation in the PBMCs of patients with RA. To further investigate the mechanism underlying the effects of LCA on the inhibition of LPS-induced proinflammatory cytokine production, $\mathrm{NF}-\kappa \mathrm{B}$ and $\mathrm{I} \kappa \mathrm{B} \alpha$ signaling was measured via western blot analysis. LCA treatment significantly decreased the phosphorylation of $N F-\kappa B$ and $I \kappa B \alpha$, but not the total protein levels of I $\mathrm{B} \alpha$ (Fig. 4).

Effects of LCA on DAB/1J mice with CIA. Mice with CIA have been frequently utilized to investigate arthritic diseases, as they possess various pathological features similar to those of human RA (37). There was no macroscopic evidence of paw erythema or edema in the normal blank control mice. As presented in Fig. 5A, arthritis symptoms in the mice 
A

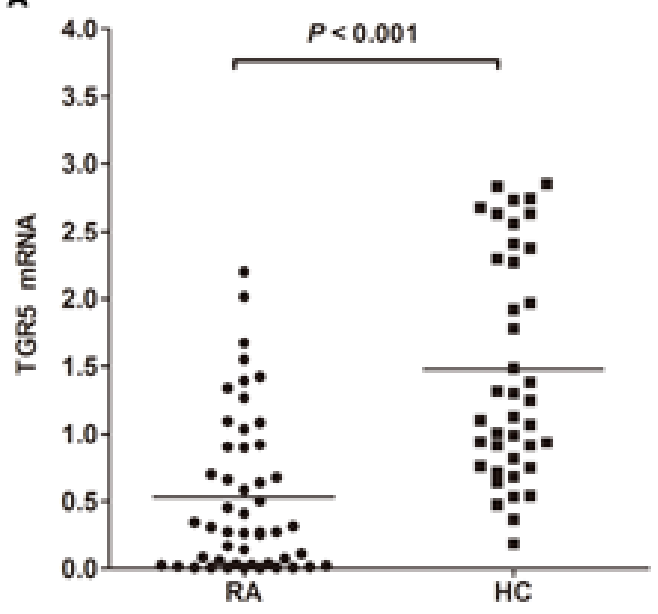

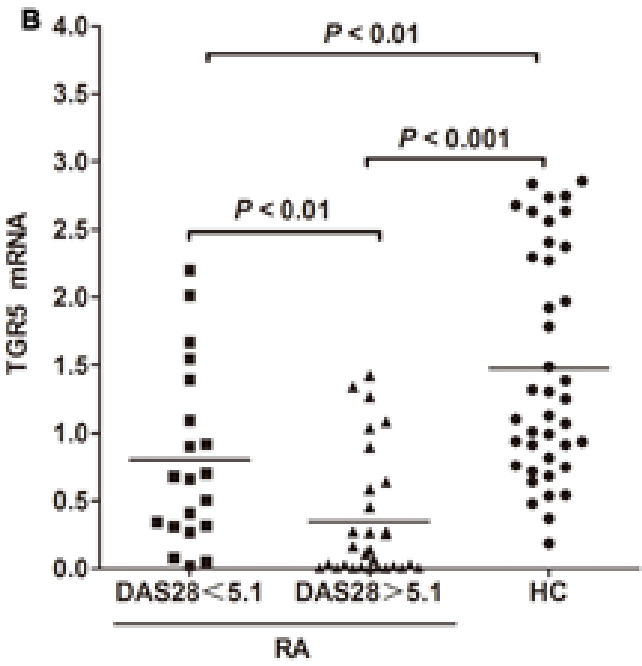

c

RA

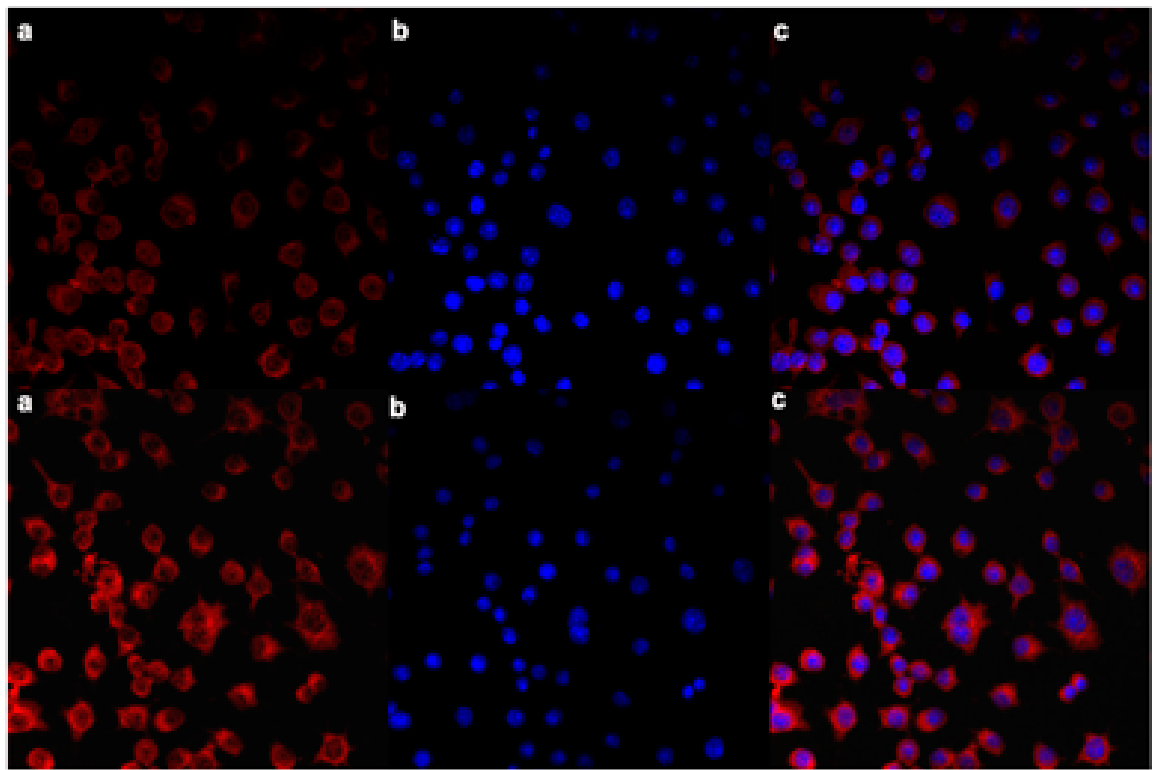

Figure 1. TGR5 expression in the PBMCs of patients with RA. (A) TGR5 mRNA expression in the PBMCs of patients with RA (n=50) compared with in PBMCs from HCs $(\mathrm{n}=40)$, as determined via reverse transcription-quantitative polymerase chain reaction analysis. (B) TGR5 expression in the high and low DAS28 groups. (C) Immunofluorescence staining of TGR5 in primary cultures of PBMCs from patients with RA and HCs. (a) TGR5 (red); (b) DAPI (blue); (c) merge. Magnification, $x 400$. Data are presented as the means \pm standard deviation. DAS28, 28-Joint Disease Activity Score; HC, healthy control; PBMC, peripheral blood mononuclear cell; RA, rheumatoid arthritis; TGR5, G-protein-coupled bile acid receptor 1.
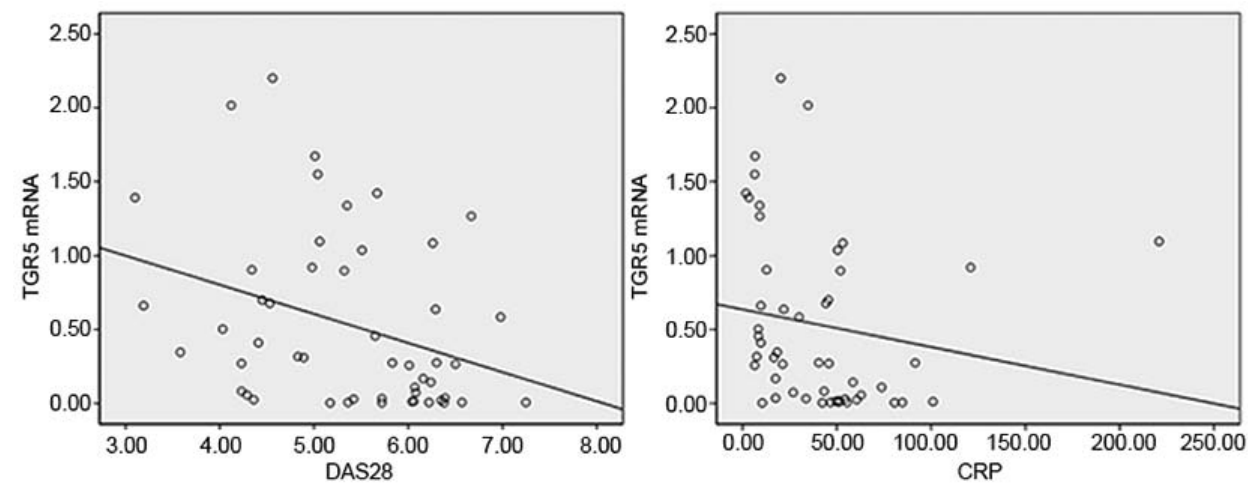

Figure 2. Correlation of TGR5 mRNA expression in the peripheral blood mononuclear cells of patients with rheumatoid arthritis with clinical parameters. CRP, C-reactive protein; DAS28, 28-Joint Disease Activity Score; TGR5, G-protein-coupled bile acid receptor 1.

with CIA progressed and maintained a high intensity from day 21 to day 42 following immunization; this was notably relieved following treatment with LCA $(10 \mathrm{mg} / \mathrm{kg} / \mathrm{day})$. From day 30 , the arthritis score was significantly decreased in the 

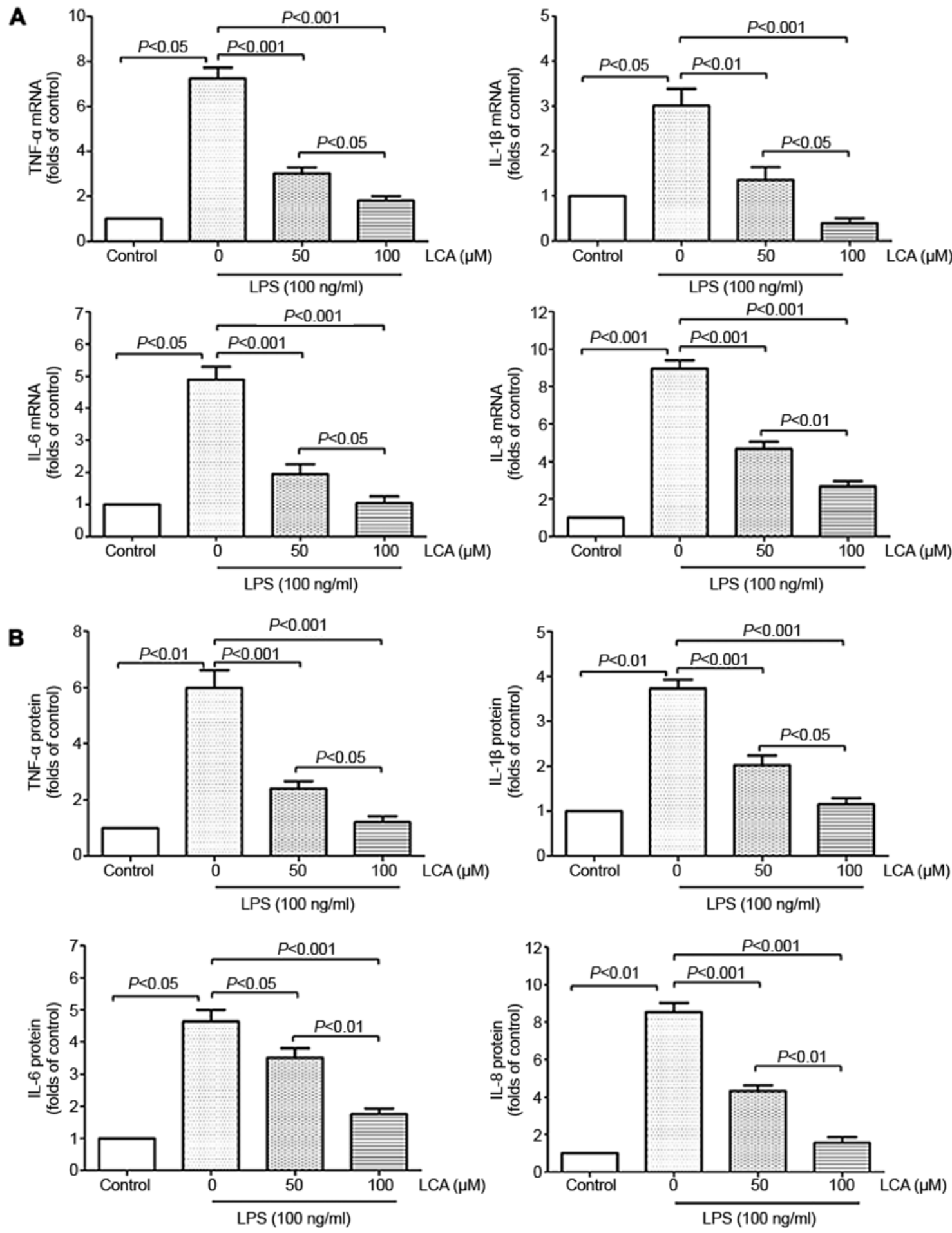

Figure 3. Inhibition of LPS-induced proinflammatory cytokine production in the PBMCs of patients with rheumatoid arthritis by LCA. (A) mRNA expression of proinflammatory cytokines in PBMCs was evaluated via reverse transcription-quantitative polymerase chain reaction. (B) Protein expression of proinflammatory cytokines in the culture medium of PBMCs was evaluated via ELISA. Data are presented as the means \pm standard deviation from three independent experiments. ELISA, enzyme-linked immunosorbent assay; IL, interleukin; LCA, lithocholic acid; LPS, lipopolysaccharide; PBMC, peripheral blood mononuclear cell; TNF- $\alpha$, tumor necrosis factor- $\alpha$.

LCA treatment group compared with in the CIA model group $(\mathrm{P}<0.05$ or 0.01$)$.

To demonstrate its anti-inflammatory effects in vivo, LCA was evaluated for its inhibition of the production of proinflammatory cytokines in mice with CIA. Cytokines, such as TNF- $\alpha$, IL-1 $\beta$, IL- 6 and IL-8, are associated with the progression and severity of arthritis (16). On day 42 , the mice were sacrificed, and blood was collected for serum separation and subsequent ELISA detection. As presented in Fig. 5B, the serum levels of the proinflammatory cytokines TNF- $\alpha$, IL-1 $\beta$, IL- 6 and IL-8 were significantly increased in the non-treated CIA mice compared with in the non-arthritic group. The increased TNF- $\alpha$, IL-1 $\beta$, IL-6, and IL-8 production was significantly suppressed by LCA treatment compared with in the non-treated mice with CIA. 
A

A
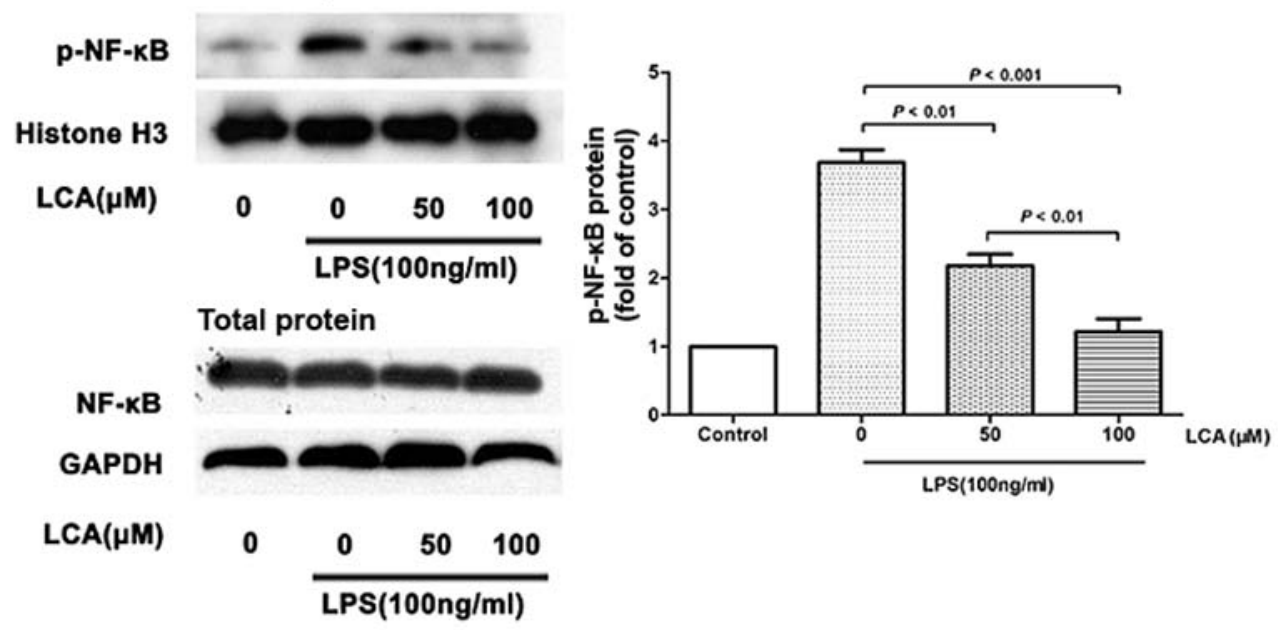

B
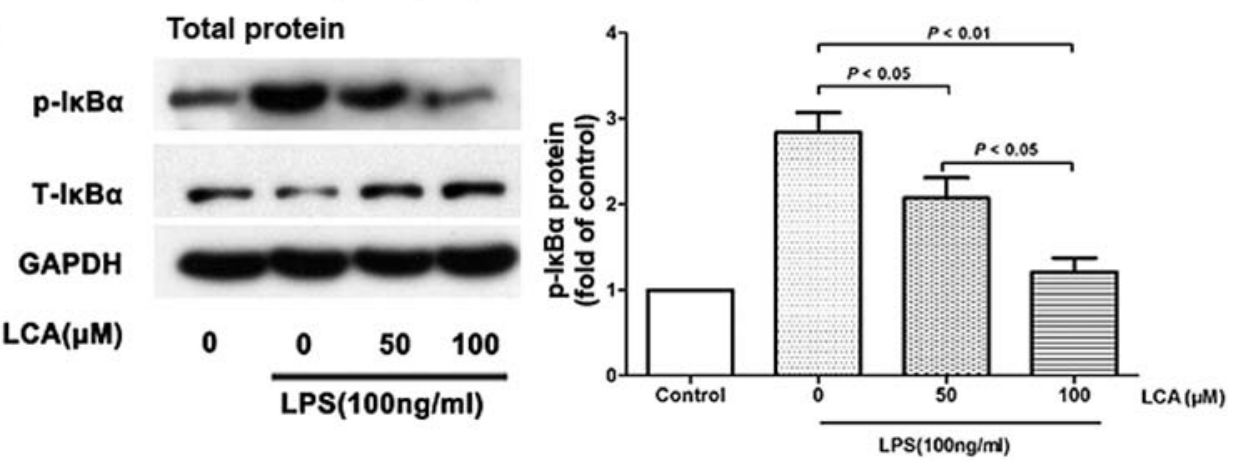

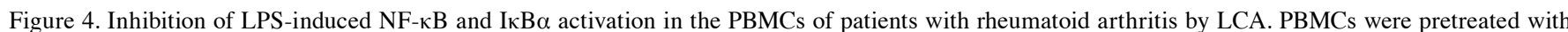
various concentrations of LCA for $60 \mathrm{~min}$, and then treated with LPS $(100 \mathrm{ng} / \mathrm{ml})$ for $12 \mathrm{~h}$; total protein and nuclear protein were collected for western blot analysis. (A) Protein expression of p-NF- $\mathrm{KB}$ in the nuclear fraction of PBMCs was evaluated via western blot analysis. (B) Protein expression of $\mathrm{p}-\mathrm{I} \kappa \mathrm{B} \alpha$ and $\mathrm{T}-\mathrm{I} \kappa \mathrm{B} \alpha$ in the whole cell extract of PBMCs was also detected via western blot analysis. Data are presented as the means \pm standard deviation from three inde-

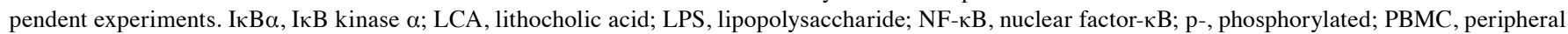
blood mononuclear cell; T-, total.

\section{Discussion}

RA is an inflammatory disease characterized by chronic inflammatory synovitis resulting in progressive joint destruction. The pathogenesis of RA involves a diverse range of cells, including monocytes/macrophages, T cells, B cells and FLSs, which produce a large number of proinflammatory cytokines, MMPs and other proteolytic enzymes. In addition, previous studies have indicated that the presence of inflammatory cells is positively correlated with synovitis score, further demonstrating the involvement of inflammatory cells in the pathophysiology of RA $(38,39)$.

Monocytic/macrophagic inflammation is central to almost all aspects that contribute to the development of RA, as it is regarded as the primary source of proinflammatory cytokines, including TNF- $\alpha$ and IL- $1 \beta$, which serve important roles in the communication between the various inflammatory cells involved in RA $(40,41)$. TGR5 has been identified as an important component of the bile acid signaling network, and its activation has been reported to control numerous physiological pathways associated with metabolic homeostasis, bile acid synthesis and inflammation. Furthermore, emerging evidence has demonstrated that TGR5 is expressed in various immune cells, including monocytes, alveolar macrophages and Kupffer cells, and it has been reported that its activation modulates inflammatory responses in these cells $(23,24,26)$; however, whether TGR5 serves a role in the regulation of PBMC inflammation in RA has yet to be fully investigated. In the present study, it was revealed that TGR5 was expressed in primary PBMCs, and that TGR5 expression was significantly downregulated in the PBMCs of patients with RA compared with in PBMCs from HCs. Additionally, TGR5 expression in PBMCs exhibited significantly negative correlations with CRP level and DAS28. Therefore, it was hypothesized that decreased TGR5 expression may potentially be involved in the pathogenesis of RA.

To investigate the effects of TGR5 on PBMC-mediated inflammation, LPS was used to induce inflammation in PBMCs, and LCA was administered to activate TGR5. It was observed that pretreatment of PBMCs with LCA potently downregulated LPS-induced TNF- $\alpha$, IL-1 $\beta$, IL- 6 and IL-8 expression, and inhibited NF- $\kappa \mathrm{B}$ and $\mathrm{I} \kappa \mathrm{B} \alpha$ phosphorylation in a concentration-dependent manner; this finding is consistent with previous observations demonstrating that TGR5 activation attenuates proinflammatory cytokine production in monocytes/macrophages via suppression of the nuclear translocation of NF- $\mathrm{KB}(23,27,42)$. Högenauer et al (42) indicated that TGR5 activation inhibits LPS-induced TNF- $\alpha$ and IL-12 

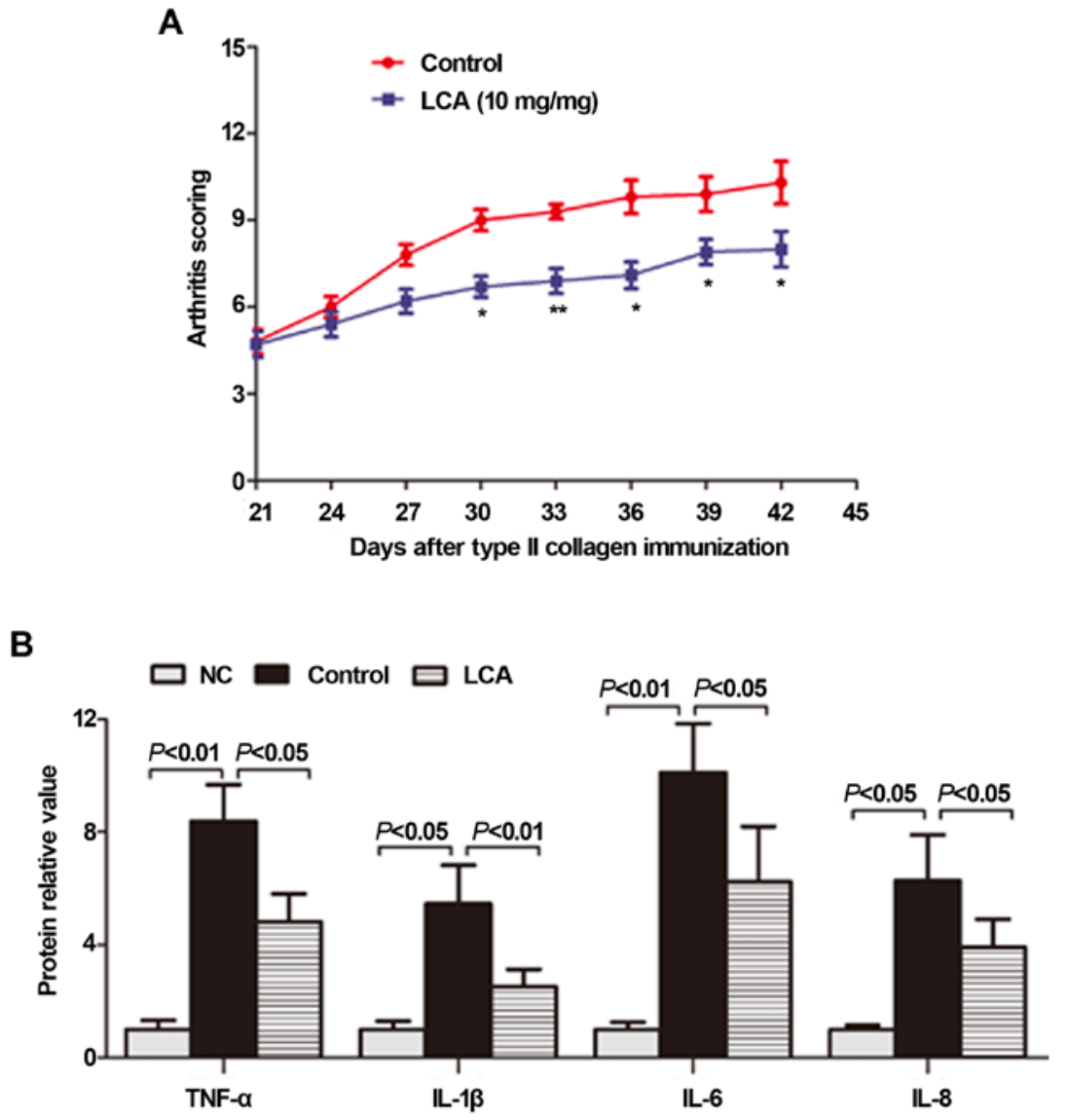

Figure 5. Effects of LCA on DAB/1J mice with CIA. DAB/1J mice with CIA were orally treated with LCA (10 mg/kg/day) from day 21 to day 42 . (A) Arthritis scores of mice with CIA. (B) Following LCA treatment, the levels of TNF- $\alpha$, IL-1 $\beta$, IL- 6 and IL-8 in the plasma of mice were determined via ELISA. Data are presented as the means \pm standard deviation from three independent experiments. ${ }^{*} \mathrm{P}<0.05,{ }^{* *} \mathrm{P}<0.01$ vs. Control. CIA, collagen II-induced arthritis; Control group, mice with CIA not treated with LCA; LCA, lithocholic acid; NC group, normal blank control mice; LCA group, mice with CIA treated with LCA.

release from PBMCs and in mice. Additionally, it has been reported that TGR5 activation does not affect production of the anti-inflammatory cytokine IL-10, it only suppresses the secretion of proinflammatory cytokines TNF- $\alpha$, IL- 6 and IL-12p40 by primary human macrophages (27). Therefore, inhibition of the release of different proinflammatory cytokines may be associated with activation of TGR5 by various agonists in human monocytes/macrophages, with or without RA. The present findings indicated that TGR5 is a potential suppressor of NF- $\mathrm{NB}$-dependent inflammatory responses; however, the nature of the interaction between TGR5 and NF- $\kappa \mathrm{B} / \mathrm{I} \kappa \mathrm{B} \alpha$ in the PBMCs of patients with RA remains unknown. It has been reported that TGR5 serves an important role in immunological regulation via cyclic adenosine monophosphate, a second messenger with immunoregulatory functions $(25,43)$. Additionally, a previous study indicated that TGR5 promotes the activation of cytosolic protein $\beta$-arrestin 2 , which interacts with $\mathrm{I} \kappa \mathrm{B} \alpha$ following bacterial antigen stimulation in mouse livers, suppressing the production of TNF- $\alpha$ (26). Therefore, further studies into the mechanisms underlying the modulation of the activity of NF- $\kappa \mathrm{B}$ and $\mathrm{I} \kappa \mathrm{B} \alpha$ in the PBMCs of patients with RA by TGR5 are required.

$\mathrm{NF}-\kappa \mathrm{B}$ is a family of ubiquitously expressed transcription factors that serve crucial roles in the majority of inflammatory and immune responses (15). Constitutive NF- $\kappa \mathrm{B}$ activation has been associated with the pathogenesis of numerous diseases, including inflammatory and rheumatic diseases (RA and osteoarthritis), atherosclerosis, asthma, multiple sclerosis, chronic inflammatory demyelinating inflammatory bowel disease and diabetes (14). Additionally, studies on emerging animal models of inflammatory arthritis support the hypothesis that $\mathrm{NF}-\kappa \mathrm{B}$ is a predominant adaptor in the development and progression of arthritis in vivo $(44,45)$. In the present study, it was revealed that TGR5 activation significantly inhibited $\mathrm{NF}-\kappa \mathrm{B}$ activity in vitro, implying that TGR5 activation may potentially alleviate arthritis symptoms and inflammation of RA in vivo. CIA mouse models with pathological features similar to those of human RA are used to study arthritic diseases. It was observed that TGR5 activation by LCA significantly suppressed inflammation and the progression of arthritis in mice with CIA, as determined by their arthritis score. RA is characterized by chronic inflammatory synovitis and joint destruction; thus, future experiments will aim to identify the mechanisms underlying the effects of TGR5 on synovitis and joint destruction in patients with RA or mice with CIA.

In RA, activated immune cells secrete large quantities of proinflammatory cytokines. TNF- $\alpha$ is a potent inducer of inflammation, and IL-6 and IL-1 $\beta$ are downstream mediators of TNF- $\alpha$, together serving significant roles in the progression of inflammatory synovitis and joint destruction in RA $(46,47)$. IL-8 is involved in leukocyte recruitment to 
a diseased synovium (48). Agents that inhibit TNF- $\alpha$, IL-6 and IL-1 are frequently used in clinical settings therapeutically (49). In the present study, TGR5 activation demonstrated therapeutic effects against RA by downregulating the levels of TNF- $\alpha$, IL-1 $\beta$, IL- 6 and IL- 8 in the plasma of mice with CIA in vivo. TGR5 activation also significantly suppressed LPS-induced TNF- $\alpha$, IL-1 $\beta$, IL- 6 and IL- 8 expression in PBMCs in vitro. These results indicated that TGR5 activation may inhibit proinflammatory cytokine expression in monocytes/macrophages and further reduce inflammation in RA; however, the influence of TGR5 on other immune cells and tissues of patients with RA or mice with CIA remains unclear and requires further study. Monocytes can differentiate into proinflammatory microbicidal M1 macrophages or anti-inflammatory M2 macrophage subtypes (50). Macrophages are stimulated to differentiate into M1 macrophages by infectious microorganism-associated molecules such as LPS and inflammatory cytokines such as interferon- $\gamma$ (51). M1 macrophages can produce inflammatory cytokines, including interleukin IL-1 $\beta$, TNF-a and IL-6 (52). Högenauer et al (42) demonstrated that TGR5 activation stabilizes the phenotype of noninflammatory M2-like type cells during the differentiation of monocytes into macrophages. The effect of TGR5 on macrophage differentiation in mice with CIA requires further investigation.

Collectively, TGR5 activation attenuated the expression of TNF- $\alpha$, IL-1 $\beta$, IL- 6 and IL- 8 via inhibition of NF- $\kappa$ B activity in LPS-stimulated PBMCs in vitro, decreased the levels of TNF- $\alpha$, IL-1 $\beta$, IL- 6 and IL- 8 in the plasma of mice with CIA in vivo, and hindered the progression of arthritis in mouse models of CIA, as determined by the arthritis score. RA has also been reported to have improved during jaundice, suggesting that TGR5 activation may provide a novel target for the treatment of RA (53-55). Future studies should investigate cases of RA with obstructive jaundice, to further determine the potential role and effects of TGR5 in RA.

\section{Acknowledgements}

Not applicable.

\section{Funding}

The present study was supported by a grant from the National Natural Science Foundation of China (grant no. 81401631) and Education of Zhejiang Province (grant no. Y201737942).

\section{Availability of data and materials}

The datasets used and/or analyzed during the current study are available from the corresponding author on reasonable request.

\section{Authors' contributions}

JJZ and ZYL participated in study development and collection of patient samples, performed experiments, and actively wrote the first draft of the manuscript. CLL was involved in collecting and analyzing part of the clinical data. LMZ participated in analyzing the data from in vitro cell experiments and revising the manuscript. All authors approved the final manuscript.

\section{Ethics approval and consent to participate}

The study protocol was approved by the the Institutional Animal and Clinical Committees of Hunan Cancer Hospital and written informed consent was obtained from all participants in the study.

\section{Patient consent for publication}

Written informed consent was obtained from all participants.

\section{Competing interests}

The authors declare that they have no competing interests.

\section{References}

1. Siebert S, Tsoukas A, Robertson J and McInnes I: Cytokines as therapeutic targets in rheumatoid arthritis and other inflammatory diseases. Pharmacol Rev 67: 280-309, 2015.

2. Choy EH and Panayi GS: Cytokine pathways and joint inflammation in rheumatoid arthritis. N Engl J Med 344: 907-916, 2001.

3. Karsdal MA, Woodworth T, Henriksen K, Maksymowych WP, Genant H, Vergnaud P, Christiansen C, Schubert T, Qvist P, Schett $\mathrm{G}$, et al: Biochemical markers of ongoing joint damage in rheumatoid arthritis-current and future applications, limitations and opportunities. Arthritis Res Ther 13: 215, 2011.

4. Wang Q, Ma Y, Liu D, Zhang L and Wei W: The roles of B cells and their interactions with fibroblast-like synoviocytes in the pathogenesis of rheumatoid arthritis. Int Arch Allergy Immunol 155: 205-211, 2011.

5. Lefevre S, Meier FM, Neumann E and Muller-Ladner U: Role of synovial fibroblasts in rheumatoid arthritis. Curr Pharm Des 21: 130-141, 2015.

6. Roberts CA, Dickinson AK and Taams LS: The interplay between monocytes/macrophages and CD4(+) T cell subsets in rheumatoid arthritis. Front Immunol 6: 571, 2015.

7. Davignon JL, Hayder M, Baron M, Boyer JF, Constantin A, Apparailly F, Poupot R and Cantagrel A: Targeting monocytes/macrophages in the treatment of rheumatoid arthritis. Rheumatology (Oxford) 52: 590-598, 2013.

8. Kinne RW, Stuhlmuller B and Burmester GR: Cells of the synovium in rheumatoid arthritis. Macrophages. Arthritis Res Ther 9: 224, 2007.

9. Schett G: Cells of the synovium in rheumatoid arthritis. Osteoclasts. Arthritis Res Ther 9: 203, 2007.

10. Yokota K: Inflammation and osteoclasts. Nihon Rinsho Men'eki Gakkai kaishi 40: 367-376, 2017 (In Japanese).

11. Alam J, Jantan I and Bukhari SNA: Rheumatoid arthritis: Recent advances on its etiology, role of cytokines and pharmacotherapy. Biomed Pharmacother 92: 615-633, 2017.

12. Mulherin D, Fitzgerald O and Bresnihan B: Synovial tissue macrophage populations and articular damage in rheumatoid arthritis. Arthritis Rheum 39: 115-124, 1996.

13. Yanni G, Whelan A, Feighery C and Bresnihan B: Synovial tissue macrophages and joint erosion in rheumatoid arthritis. Ann Rheum Dis 53: 39-44, 1994.

14. Aravilli RK, Vikram SL and Kohila V: Phytochemicals as potential antidotes for targeting NF- $\kappa \mathrm{B}$ in rheumatoid arthritis. 3 Biotech 7: 253, 2017.

15. Roman-Blas JA and Jimenez SA: NF- $\kappa B$ as a potential therapeutic target in osteoarthritis and rheumatoid arthritis. Osteoarthritis and Cartilage 14: 839-848, 2006.

16. McInnes IB and Schett G: Cytokines in the pathogenesis of rheumatoid arthritis. Nat Rev Immunol 7: 429-442, 2007.

17. Schaap FG, Trauner M and Jansen PL: Bile acid receptors as targets for drug development. Nat Rev Gastroenterol Hepatol 11: 55-67, 2014.

18. Lin TH, Tang $\mathrm{CH}$, Wu K, Fong YC, Yang RS and Fu WM: 15-deoxy- $\Delta(12,14)$-prostaglandin-J2 and ciglitazone inhibit TNF- $\alpha$-induced matrix metalloproteinase 13 production via the antagonism of NF- $\kappa \mathrm{B}$ activation in human synovial fibroblasts. J Cell Physiol 226: 3242-3250, 2011. 
19. Yu DD, Sousa KM, Mattern DL, Wagner J, Fu X, Vaidehi N, Forman BM and Huang W: Stereoselective synthesis, biological evaluation, and modeling of novel bile acid-derived G-protein coupled bile acid receptor 1 (GP-BAR1, TGR5) agonists. Bioorg Med Chem 23: 1613-1628, 2015.

20. Pols TW: TGR5 in inflammation and cardiovascular disease. Biochem Soc Trans 42: 244-249, 2014.

21. Russell DW and Setchell KD: Bile acid biosynthesis. Biochemistry 31: 4737-4749, 1992.

22. Pols TW, Noriega LG, Nomura M, Auwerx J and Schoonjans K: The bile acid membrane receptor TGR5 as an emerging target in metabolism and inflammation. J Hepatol 54: 1263-1272, 2011.

23. Kawamata Y, Fujii R, Hosoya M, Harada M, Yoshida H, Miwa M, Fukusumi S, Habata Y, Itoh T, Shintani Y, et al: A G protein-coupled receptor responsive to bile acids. J Biol Chem 278: 9435-9440, 2003.

24. Keitel V, Donner M, Winandy S, Kubitz R and Haussinger D: Expression and function of the bile acid receptor TGR5 in Kupffer cells. Biochem Biophys Res Commun 372: 78-84, 2008.

25. Pols TW, Nomura M, Harach T, Lo Sasso G, Oosterveer MH, Thomas C, Rizzo G, Gioiello A, Adorini L, Pellicciari R, et al: TGR5 activation inhibits atherosclerosis by reducing macrophage inflammation and lipid loading. Cell Metab 14: 747-757, 2011.

26. Wang YD, Chen WD, Yu D, Forman BM and Huang W: The G-protein-coupled bile acid receptor, Gpbarl (TGR5), negatively regulates hepatic inflammatory response through antagonizing nuclear factor $\kappa$ light-chain enhancer of activated B cells $(\mathrm{NF}-\kappa \mathrm{B})$ in mice. Hepatology 54: 1421-1432, 2011

27. Haselow K, Bode JG, Wammers M, Ehlting C, Keitel V, Kleinebrecht L, Schupp AK, Häussinger D and Graf D: Bile acids PKA-dependently induce a switch of the IL-10/IL-12 ratio and reduce proinflammatory capability of human macrophages. J Leukoc Boil 94: 1253-1264, 2013.

28. Arnett FC, Edworthy SM, Bloch DA, McShane DJ, Fries JF Cooper NS, Healey LA, Kaplan SR, Liang MH and Luthra HS: The American Rheumatism Association 1987 revised criteria for the classification of rheumatoid arthritis. Arthritis Rheum 31: 315-324, 1988

29. Aletaha D, Neogi T, Silman AJ, Funovits J,Felson DT, Bingham CO III, Birnbaum NS, Burmester GR, Bykerk VP, Cohen MD, et al: 2010 Rheumatoid arthritis classification criteria: An American college of rheumatology/european league against rheumatism collaborative initiative. Arthritis Rheum 62: 2569-2581, 2010.

30. Koh ET, Seow A, Pong LY, Koh WH, Chan L, Howe HS, Lim TH and Low CK: Cross cultural adaptation and validation of the Chinese health assessment questionnaire for use in rheumatoid arthritis. J Rheumatol 25: 1705-1708, 1998.

31. Anderson J, Caplan L, Yazdany J, Robbins ML, Neogi T, Michaud K, Saag KG, O'Dell JR and Kazi S: Rheumatoid arthritis disease activity measures: American college of rheumatology recommendations for use in clinical practice. Arthritis Care Res (Hoboken) 64: 640-647, 2012.

32. Livak KJ and Schmittgen TD: Analysis of relative gene expression data using real-time quantitative PCR and the 2(-Delta Delta C(T)) method. Methods 25: 402-408, 2001.

33. Jones-Bolin S: Guidelines for the care and use of laboratory animals in biomedical research. Curr Protoc Pharmacol Appendix 4: Appendix 4B, 2012

34. Brand DD, Latham KA and Rosloniec EF: Collagen-induced arthritis. Nat Protoc 2: 1269-1275, 2007.

35. Yoo SA, Park BH, Park GS, Koh HS, Lee MS, Ryu SH, Miyazawa K, Park SH, Cho CS and Kim WU: Calcineurin is expressed and plays a critical role in inflammatory arthritis. J Immunol 177: 2681-2690, 2006.

36. Lee H, Nah SS, Chang SH, Kim HK, Kwon JT, Lee S, Cho IH, Lee SW, Kim YO, Hong SJ and Kim HJ: PER2 is downregulated by the LPS-induced inflammatory response in synoviocytes in rheumatoid arthritis and is implicated in disease susceptibility. Mol Med Rep 16: 422-428, 2017.

37. Cho YG, Cho ML, Min SY and Kim HY: Type II collagen autoimmunity in a mouse model of human rheumatoid arthritis. Autoimmun Rev 7: 65-70, 2007.

38. Mo YQ, Dai L, Zheng DH, Zhu LJ, Wei XN, Pessler F, Shen J and Zhang BY: Synovial infiltration with CD79a-positive B cells, bu not other B cell lineage markers, correlates with joint destruction in rheumatoid arthritis. J Rheumatol 38: 2301-2308, 2011
39. Zhu LJ, Dai L, Zheng DH, Mo YQ, Ou-Yang X, Wei XN, Shen J and Zhang BY: Upregulation of tumor necrosis factor receptor-associated factor 6 correlated with synovitis severity in rheumatoid arthritis. Arthritis Res Ther 14: R133, 2012.

40. Smeets TJ, Barg EC, Kraan MC, Smith MD, Breedveld FC and Tak PP: Analysis of the cell infiltrate and expression of proinflammatory cytokines and matrix metalloproteinases in arthroscopic synovial biopsies: Comparison with synovial samples from patients with end stage, destructive rheumatoid arthritis. Ann Rheum Dis 62: 635-638, 2003.

41. Proudman SM, Cleland LG and Mayrhofer G: Effects of tumor necrosis factor-alpha, interleukin 1beta, and activated peripheral blood mononuclear cells on the expression of adhesion molecules and recruitment of leukocytes in rheumatoid synovial xenografts in SCID mice. J Rheumatol 26: 1877-1889, 1999.

42. Högenauer K, Arista L, Schmiedeberg N, Werner G, Jaksche H, Bouhelal R, Nguyen DG, Bhat BG, Raad L, Rauld C and Carballido JM: G-protein-coupled bile acid receptor 1 (GPBAR1, TGR5) agonists reduce the production of proinflammatory cytokines and stabilize the alternative macrophage phenotype. J Med Chem 57: 10343-10354, 2014.

43. Ichikawa R, Takayama T, Yoneno K, Kamada N, Kitazume MT, Higuchi H, Matsuoka K, Watanabe M, Itoh H, Kanai T, et al: Bile acids induce monocyte differentiation toward interleukin-12 hypo-producing dendritic cells via a TGR5-dependent pathway. Immunology 136: 153-162, 2012.

44. Makarov SS: NF-kappa B in rheumatoid arthritis: A pivotal regulator of inflammation, hyperplasia, and tissue destruction. Arthritis Res 3: 200-206, 2001.

45. Mor A, Abramson SB and Pillinger MH: The fibroblast-like synovial cell in rheumatoid arthritis: A key player in inflammation and joint destruction. Clin Immunol 115: 118-128, 2005.

46. Zheng Y, Sun L, Jiang T, Zhang D, He D and Nie H: TNFalpha promotes Th17 cell differentiation through IL-6 and IL-1beta produced by monocytes in rheumatoid arthritis. J Immunol Res 2014: 385352, 2014.

47. Xin W, Huang C, Zhang X, Xin S, Zhou Y, Ma X, Zhang D, Li Y, Zhou S, Zhang D, et al: Methyl salicylate lactoside inhibits inflammatory response of fibroblast-like synoviocytes and joint destruction in collagen-induced arthritis in mice. Br J Pharmacol 171: 3526-3538, 2014.

48. Szekanecz Z, Kim J and Koch AE: Chemokines and chemokine receptors in rheumatoid arthritis. Semin Immunol 15: 15-21, 2003.

49. Smolen JS, Landewe R, Bijlsma J, Burmester G, Chatzidionysiou K, Dougados M, Nam J, Ramiro S, Voshaar M, van Vollenhoven $\mathrm{R}$, et al: EULAR recommendations for the management of rheumatoid arthritis with synthetic and biological disease-modifying antirheumatic drugs: 2016 update. Ann Rheum Dis 76: 960-977, 2017.

50. Italiani P and Boraschi D: From monocytes to M1/M2 macrophages: Phenotypical vs. Functional differentiation. Front Immunol 5: 514, 2014.

51. Dey A, Allen J and Hankey-Giblin PA: Ontogeny and polarization of macrophages in inflammation: Blood monocytes versus tissue macrophages. Front Immunol 5: 683, 2015.

52. Gordon S and Taylor PR: Monocyte and macrophage heterogeneity. Nat Rev Immunol 5: 953-964, 2005.

53. Crocker I, Lawson $\mathrm{N}$ and Fletcher J: Effect of pregnancy and obstructive jaundice on inflammatory diseases: The work of P S hench revisited. Ann Rheum Dis 61: 307-310, 2002.

54. Rutkauskaite E, Zacharias W, Schedel J, Müller-Ladner U, Mawrin C, Seemayer CA, Alexander D, Gay RE, Aicher WK, Michel BA, et al: Ribozymes that inhibit the production of matrix metalloproteinase 1 reduce the invasiveness of rheumatoid arthritis synovial fibroblasts. Arthritis Rheum 50: 1448-1456, 2004.

55. Ma JD, Zhou JJ, Zheng DH, Chen LF, Mo YQ, Wei XN, Yang LJ and Dai L: Serum matrix metalloproteinase-3 as a noninvasive biomarker of histological synovitis for diagnosis of rheumatoid arthritis. Mediators Inflammation 2014: 179284, 2014

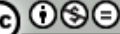

This work is licensed under a Creative Commons Attribution-NonCommercial-NoDerivatives 4.0 International (CC BY-NC-ND 4.0) License. 